\title{
Doença de Hansen: Uma Forma de Eritema Figurado
}

\section{Hansen Disease: A Type of Figurate Erythema}

\author{
Rebeca CALADO ${ }^{1}$, José Carlos CARDOSO ${ }^{1}$, André PINHO ${ }^{1}$ \\ Acta Med Port 2021 Oct;34(10):696-697 • https://doi.org/10.20344/amp.13348
}

Palavras-chave: Lepra Multibacilar; Mycobacterium leprae

Keywords: Leprosy, Multibacillary; Mycobacterium leprae

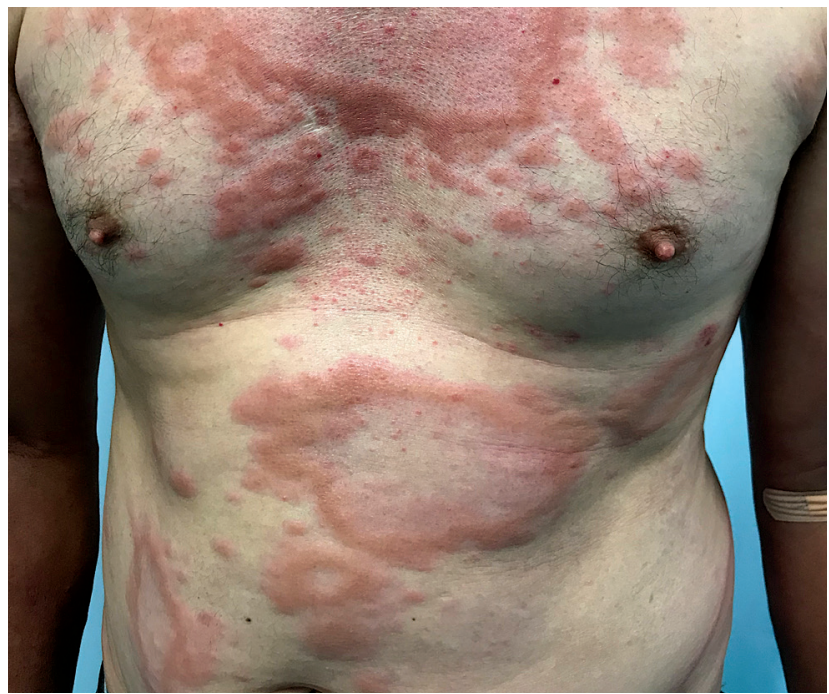

Figura 1 - Numerosas placas anulares ou policíclicas eritematosas, de bordos edematosos, bem definidos internamente e mal definidos externamente e com clareamento central, com distribuição assimétrica, com aspeto em 'queijo suíço'

Doente do sexo masculino, de 42 anos, apresentava à observação placas eritematoedematosas policíclicas com hipostesia central, distribuídas assimetricamente pelo tronco e membros, desde há cinco anos (Fig. 1). Apresentava perda da sensibilidade álgica, táctil e térmica em 'meia-luva', na ausência de nervos periféricos palpáveis. A biópsia cutânea revelou infiltrado dérmico com histiócitos espumosos com tropismo perineural (Fig. 2). A coloração Ziehl-Nielsen evidenciou numerosos bacilos ácido-álcool resistentes intracelulares. Estabeleceu-se o diagnóstico de lepra (doença de Hansen) multibacilar e iniciou-se terapêutica tripla - rifampicina, clofazimina, dapsona - durante 12 meses, com melhoria progressiva do quadro cutâneo e estabilização das queixas neurológicas. A lepra é uma infeção crónica da pele e nervos periféricos, por Mycobacterium leprae, que pode afetar olhos, mucosas, ossos e testículos. ${ }^{1,2} \mathrm{~A}$ clínica reflete o estado imune do hospedeiro - lepra lepromatosa, com múltiplas lesões cutâneas e resposta humoral (células Th2); lepra tuberculóide, com envolvimento

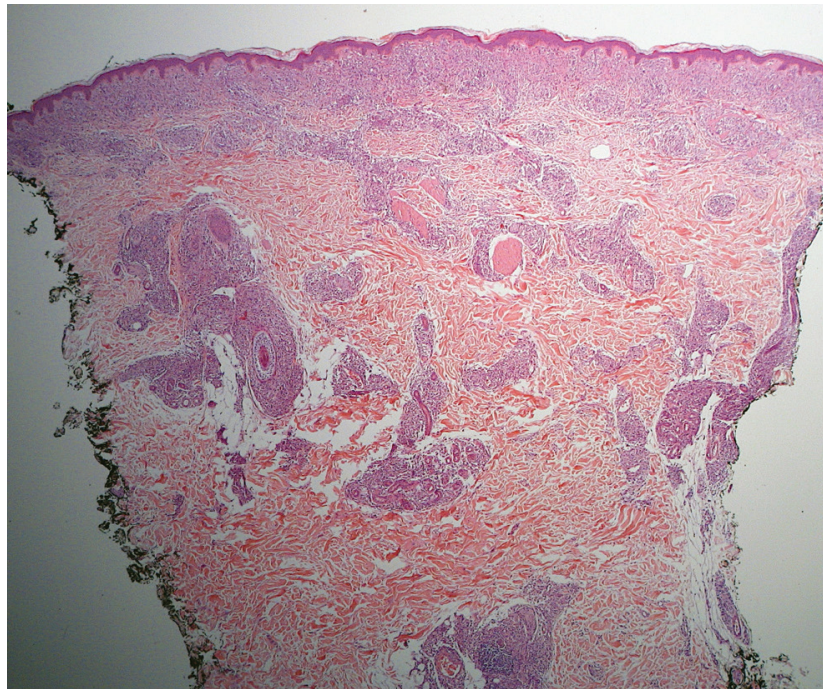

Figura 2 - Infiltrado predominantemente histiocitário na derme superificial e profunda, com padrão mais difuso em superfície, aspeto granulomatoso em profundidade e marcado tropismo perineural, periécrino e perifolicular. Fina zona de Grenz separando epiderme do infiltrado. (Hematoxilina-Eosina; x40).

neurológico predominante, cutâneo paucilesional e resposta predominantemente celular (Th1); e lepra borderline, se sobreposição de caraterísticas anteriores, como no presente caso. ${ }^{3}$

\section{CONTRIBUTO DOS AUTORES}

RC: Recolha dos dados clínicos; revisão bibliográfica; elaboração do manuscrito.

JCC: Análise histológica, elaboração e revisão do manuscrito.

AP: Recolha dos dados clínicos; biópsia cutânea; revisão do manuscrito.

\section{PROTECÇÃO DE PESSOAS E ANIMAIS}

Os autores declaram que os procedimentos seguidos estavam de acordo com os regulamentos estabelecidos pelos responsáveis da Comissão de Investigação Clínica e Ética e de acordo com a Declaração de Helsínquia da Associação Médica Mundial actualizada em 2013.

\footnotetext{
1. Serviço de Dermatologia. Centro Hospitalar e Universitário de Coimbra. Coimbra. Portugal.

$\triangle$ Autor correspondente: Rebeca Calado. a.rebecalado@.gmail.com

Recebido: 29 de dezembro de 2019 - Aceite: 19 de fevereiro de 2020 - First published: 07 de setembro de 2021 - Online issue published: 01 de outubro de 2021 Copyright $\odot$ Ordem dos Médicos 2021
} 


\section{CONFIDENCIALIDADE DOS DADOS}

Os autores declaram ter seguido os protocolos do seu centro de trabalho acerca da publicação de dados.

\section{CONSENTIMENTO INFORMADO}

Obtido.

\section{CONFLITOS DE INTERESSE}

Os autores declaram não ter qualquer conflito de interesse relativamente ao presente artigo.

\section{FONTES DE FINANCIAMENTO}

Não foi utilizada nenhuma bolsa ou subsídio para a realização do trabalho.

\section{REFERÊNCIAS}

1. Eichelmann K, González González SE, Salas-Alanis JC, Ocampo-Candiani J. Lepra: puesta al día. Definición, patogénesis, clasificación, diagnóstico y tratamiento. Actas Dermosifiliogr. 2013;104:554-63.

2. Shiva Raj KC, Geetika KC, Gyawali P, Singh M, Sijapati MJ. Leprosy - eliminated and forgotten: a case report. J Med Case Reports. $2019 ; 13: 276$.

3. de Sousa JR, Sotto MN, Simões Quaresma JA. Leprosy as a vomplex infection: breakdown of the Th1 and Th2 immune paradigm in the immunopathogenesis of the disease. Front Immunol. 2017;8:1635. 